\title{
Total thyroidectomy vs completion thyroidectomy for thyroid nodules with indeterminate cytology/follicular proliferation: a single-centre experience
}

Giuseppe Sena* (D), Gaetano Gallo, Nadia Innaro, Noemi Laquatra, Martina Tolone, Rosario Sacco and Giuseppe Sammarco

\begin{abstract}
Background: Despite total thyroidectomy (TT) is the most practiced procedure for a preoperatively diagnosed neoplastic lesion, according to the ATA guidelines, many surgeons perform completion thyroidectomy (CT) after hemithyroidectomy for patients with preoperative follicular proliferation/indeterminate cytology who are diagnosed with malignancy. CT has a higher complication rate than the primary procedure. The primary endpoint of our study is to compare the morbidity rate after $\mathrm{CT}$ with that after primary $\Pi \mathrm{T}$ in patients with follicular proliferation/ indeterminate cytology.
\end{abstract}

Methods: We retrospectively reviewed 237 patients who underwent thyroid surgery from 2009 to 2018 at our institution. We recruited only patients with follicular proliferation/indeterminate cytology and excluded those undergoing lymphadenectomies and thyroidectomies for benign pathology and staged thyroidectomies after intraoperative documentation of a RLN lesion. One hundred eighty-six of these patients underwent $\pi$, and fifty-one underwent $\mathrm{CT}$ for the detection of differentiated thyroid cancer at the histological exam.

Results: No differences were found in the total complication rates between the two groups (OR 0,76, 95\% Cl 0.35$1.65, P=0.49$ ). We did not find any significant differences in the subgroup analysis. In particular, no significant differences were identified for transient hypocalcaemia (OR 1.17, 95\% Cl 0.44-3.11; $P=0,74)$, permanent hypocalcaemia $(\mathrm{OR} 1.04,95 \% \mathrm{Cl} 0.21-5.18 ; \mathrm{P}=0,95)$, transient unilateral recurrent laryngeal nerve palsy $(\mathrm{OR} 0.78$, $95 \% \mathrm{Cl} 0.21-2.81 ; \mathrm{P}=0,16)$, permanent unilateral recurrent laryngeal nerve palsy $(\mathrm{OR} 1.48,95 \% \mathrm{Cl} 0.28-7.85 ; \mathrm{P}=0$, 61 ), and haematoma (OR 1,84, 95\% Cl 0,16-20,71; $\mathrm{P}=0,61)$.

Conclusions: CT following hemithyroidectomy can be performed with acceptable morbidity in patients with thyroid nodules with preoperative indeterminate cytology/follicular proliferation.

Keywords: Total thyroidectomy, Completion thyroidectomy, Complication rates, Differentiated thyroid cancer

\footnotetext{
* Correspondence: gspp.sena@gmail.com

Department of Health Sciences, U.O. of Digestive Surgery, University of

Catanzaro, Viale Europa, 88100 Catanzaro, Italy
}

(c) The Author(s). 2019 Open Access This article is distributed under the terms of the Creative Commons Attribution 4.0 International License (http://creativecommons.org/licenses/by/4.0/), which permits unrestricted use, distribution, and reproduction in any medium, provided you give appropriate credit to the original author(s) and the source, provide a link to the Creative Commons license, and indicate if changes were made. The Creative Commons Public Domain Dedication waiver (http://creativecommons.org/publicdomain/zero/1.0/) applies to the data made available in this article, unless otherwise stated. 


\section{Background}

Differentiated thyroid carcinoma (DTC) is one of the most frequent malignancies but fortunately has an optimal prognosis [1-3]. Surgical therapy is mandatory for resolution of this condition. Unfortunately, surgical treatment of thyroid diseases is still controversial. Total thyroidectomy (TT) has been considered the best treatment for DTC with behaviours of multicentricity and bilaterality for a long time because it eliminates the potential residual tumour risk and allows better ablation of possible residual tissue with radioactive iodine [4-8]. Despite TT is the most practiced procedure for a preoperatively diagnosed neoplastic lesion, according to the ATA guidelines, many surgeons perform completion thyroidectomy $(\mathrm{CT})$ after hemithyroidectomy for patients with preoperative follicular proliferation/indeterminate cytology who are diagnosed with malignancy [9-11]. CT has a higher complication rate than the primary procedure due to adhesions and the distorted anatomy following initial neck exploration $[12,13]$. Main complications are temporary recurrent laryngeal nerve (RLN) palsy, permanent RLN palsy, temporary hypocalcaemia, permanent hypocalcaemia, haematoma, and wound infection. However, recent improvements in surgical techniques have reduced the complication rate. Therefore, the primary endpoint of our study is to compare the morbidity rate after $\mathrm{CT}$ with the morbidity rate after TT in patients with follicular proliferation/indeterminate cytology and to compare these results with published data.

\section{Methods}

In this retrospective study, we reviewed 237 patients who underwent TT or completion thyroidectomy at our institution from 2009 to 2018. We recruited only patients with follicular proliferation/indeterminate cytology and excluded those undergoing lymphadenectomies, thyroidectomies for benign diseases and staged thyroidectomies after intraoperative documentation of a RLN lesion. One hundred eighty-six of these patients underwent TT and fifty-one underwent CT for detection of DTC at the histological exam. We carried out CT three to twelve weeks after hemithyroidectomy. In all patients, we performed an US scan of the neck for assessment of the thyroid gland and locoregional nodes, measured the serum triiodothyronine (T3), thyroxin (T4), and thyroid stimulating hormone (TSH) concentrations and the blood calcium level, and performed fine needle aspiration (FNA) cytology and direct fibrolaryngoscopy. Computer tomography scanning was used selectively in cases with suspected infiltration of nearby structures. We assessed serum calcium levels routinely on postoperative day one, and we repeated this measurement until discharge on the third postoperative day. For all patients, we collected age, sex, operative procedures, preoperative cytology, histological cancer type and all postoperative complications. All interventions were carried out by the same first operator (NI). We performed all the procedures using previously $\mathrm{NIM}^{\bullet} 2.4$ system and recently $\mathrm{NIM}^{\bullet} 3.0$ system (Medtronic, Jacksonville, USA) for intraoperative (RLN) monitoring (IONM). We used standardized technique of IONM RLNs, whit vagal assessment at the beginning and at the end of surgery. Loss of signal (LOS) was defined as absence of signal or electromyography signal amplitude below $100 \mu \mathrm{V}$, lack of palpable laryngeal twitch, or visible laryngeal movement, following stimulation of the ipsilateral vagus nerve [14]. We examined transient and permanent hypocalcaemia, transient and permanent recurrent laryngeal nerve (RLN) palsy, haemorrhage and minor wound infection. Permanent and transient RLN palsy was confirmed by fibrolaryngoscopy postoperatively.

\section{Surgical technique}

TT and CT were performed using standard surgical techniques. After making a Kocher collar incision, the skin flaps were prepared, and the cervical muscular fascia was divided longitudinally along the midline of the neck. Subsequently, the upper pole was exposed and retracted, and the superior thyroid artery and vein were divided. Then, the lobe was retracted out of the wound. In this step, both the superior and inferior parathyroid glands were mobilized and retracted laterally with their vascular pedicles. As the dissection proceeded medially, the recurrent laryngeal nerve was encountered and carefully identified. Then, the terminal division branches of the inferior thyroid artery were ligated and divided. The dissection proceeded to the region of the ligament of Berry, which was divided using a Harmonic scalpel. After full mobilization of the dominant lobe, the contralateral lobe was removed, and the steps were repeated with eventual removal of the entire thyroid gland.

\section{Statistical analysis}

All patient data were collected with a dedicated electronic Microsoft Office Excel Database (Microsoft Corp, Redmond, WA, USA). Differences between groups were analysed with the Chi-square test. Odds ratios (ORs) were reported with their 95\% confidence intervals (CIs). $P$ values less than 0.05 were considered significant. The statistical analysis was performed using the SPSS 10.0 software (Statistical Software, Chicago, IL, USA).

\section{Results}

Two hundred thirty-seven patients underwent thyroid surgery from 2009 to 2018 at our institution. One hundred eighty-six patients with indeterminate results/follicular proliferation at preoperative cytology underwent 
TT (Group 1). This procedure was performed for highrisk patients, including those with a family history of cancer, previous neck irradiation, high-volume nodules, evidence of extracapsular invasion, and bilateral nodules. Fifty-one patients received CT after detection of DTC at the definitive histological exam (Group 2). These patients had previously underwent a hemithyroidectomy for the presence of single nodules with a low risk of cancer according to the ATA guidelines. In TT group 26 nodules were papillar carcinomas and 20 nodules were follicular carcinomas with a mean size of $18,6 \mathrm{~mm}(6-$ $47 \mathrm{~mm}$ ). In CT group 30 nodules were papillar carcinomas and 21 nodules were follicular carcinomas with a mean size of $15,2 \mathrm{~mm}(5-42 \mathrm{~mm})$. The clinical and pathological characteristics of the patients are shown in Table 1. Intraoperative LOS was noted in 24 (12,9\%) and $7(13,7 \%)$ cases in TT and CT groups, respectively. Unilateral temporary RLN palsy rates were 7,5\% (14/186) and 5,8 (3/51) in the TT and CT groups, respectively. The unilateral permanent RLN palsy occurred in $2,6 \%$ $(5 / 186)$ and $3,9 \%(2 / 51)$ of the patients in the TT and CT groups, respectively. Temporary hypocalcaemia was noted in $19(10,2 \%)$ and in $6(11,7 \%)$ cases in TT and CT groups respectively. The prevalence of permanent hypocalcaemia was $3,7 \%(7 / 181)$ in the TT group versus $3.9 \%(2 / 51)$ in the CT group. The haematoma rates were $1,0 \%$ in the TT group versus $1,9 \%$ in the CT group.

No difference was found in the total complication rates between the two groups (OR 0,7; 95\% CI 0.3-1.6, $P=0.4$ ). We did not find significant differences in the subgroup analysis. The postoperative complications are shown in Table 2.

\section{Discussion}

According to the ATA guidelines, patients with an indeterminate result or follicular proliferation at FNA cytology with low-risk and monolateral nodules often undergo unilateral hemithyroidectomy. A CT is performed when DTC is found at the final histological examination, because performing only a hemithyroidectomy is considered oncologically inadequate, and a consensus exists concerning complete removal of the lobe with malignant nodules. Many surgeons prefer to perform a thyroidectomy to increase the effectiveness of

Table 1 Clinical and Pathologic Characteristics of 237 patients

\begin{tabular}{llll}
\hline & Total Thyroidectomy & Completion Thyroidectomy & $\mathrm{P}$ \\
\hline Patients (\%) & $186(78)$ & $51(21)$ & 0,0001 \\
Mean Age & 51,2 & 53,9 & $\mathrm{NV}$ \\
Age $>50(\%)$ & $89(37,5)$ & $35(68,6)$ & 0,1 \\
Age $<50(\%)$ & $97(40,9)$ & $16(31,3)$ & 1,6 \\
Female (\%) & $158(66)$ & $41(80)$ & 0,05 \\
Male (\%) & $79(32)$ & $10(19)$ & 0,05 \\
\hline
\end{tabular}

adjuvant treatments and to allow adequate follow-up [15]. CT improve oncological radicality. In fact, the rate of neoplastic disease is greater than $40 \%$ in the ipsilateral residual lobe and $30 \%$ in the contralateral lobe after completion thyroidectomy [16-18]. Because the residual disease is the most important prognostic factor, a radical resection reduces loco-regional recurrence and distance diffusion $[19,20]$, as well as low-risk carcinoma [21, 22]. After execution of a CT, the thyroglobulin dosage is an important prognostic indicator. Moreover, the removal of all thyroid tissue increases the effectiveness of radioiodine therapy for the elimination of any residual neoplastic foci. The same surgeon advocates the possibility of ablation of the remaining thyroid with I131 radiometabolic therapy. However, this method uses different dosage ranges and does not allow removal of remaining large glands. In addition, a high dosages of radioactive iodine favor the onset of pulmonary fibrosis, temporary bone marrow suppression, and leukaemia [23]. Therefore, this method does not result in the desired benefits. $\mathrm{CT}$ is traditionally characterized by a high complication rate, and complications are the reason for fear and hesitation on the part of surgeons. Complications occur due to the presence of adhesions, which make dissection difficult $[12,13]$. However, the literature shows a low complication rate due to improvement surgical techniques and high-volume surgeons. In a 2015 meta-analysis that included 7 studies and 1,208 patients and compared the complication rates between CT and primary TT for differentiated thyroid cancer, Li et al. did not find statistically significant differences in the presence of temporary recurrent laryngeal nerve (RLN) palsy, permanent RLN palsy, temporary hypocalcaemia, permanent hypocalcaemia, haematoma, and wound infection. Indeed, in this work, the temporary RLN palsy occurred in $10.1 \%$ of patients in the CT group versus $8,1 \%$ in TT groups, respectively. The permanent RLN palsy was noted in $1.8 \%$ of patients in the CT $(12 / 682)$ groups and $1.1 \%$ in TT (7/655) groups, respectively. The Temporary hypocalcaemia rates were $14.9 \%$ in CT group versus $15.4 \%$ in the TT group, and the rates of permanent hypocalcaemia were $2.8 \%$ in the CT group versus $3.3 \%$ in the TT group [24]. Based on our experience with 237 patients over an approximately 10-year period, we compared TT with CT only in patients with preoperative cytology showing indeterminate results/follicular proliferation of the thyroid nodule. We report a $5,8 \%$ rate of transient unilateral RLN palsy, 3,9\% of permanent RLN unilateral palsy, 11, $7 \%$ of transient hypocalcaemia and $3,9 \%$ of permanent hypocalcaemia in the CT group and 7,5\% rate of transient unilateral RLN palsy, 2,6\% of permanent RLN unilateral palsy, $10,21 \%$ of transient hypocalcaemia and 3,7\% of permanent hypocalcaemia in the TT group. These results were consistent with the experiences of other 
Table 2 Post-operative complications

\begin{tabular}{llll}
\hline & Total Thyroidectomy & Completion Thyroidectomy & Odds Ratio \\
\hline Temporary Hypocalcemia (\%) & $19(10,2)$ & $6(11.7)$ & $1,195 \% \mathrm{Cl}(0,4-3,1) \mathrm{p}=0,7$ \\
Permanent Hypocalcemia (\%) & $7(3,7)$ & $2(3,9)$ & $1,095 \% \mathrm{Cl}(0,2-5,1) \mathrm{p}=0,9$ \\
Temporary RLN Palsy (Unilateral) (\%) & $14(7,5)$ & $3(5,8)$ & $0,795 \% \mathrm{Cl}(0,2-2,8) \mathrm{p}=0,1$ \\
Permanent RLN Palsy (Unilateral)(\%) & $5(2.6)$. & $2(3,9)$ & $1,495 \% \mathrm{Cl}(0,2-7,8) \mathrm{p}=0,6$ \\
Hematoma (\%) & $2(1,0)$ & $1(1,9)$ & $1,895 \% \mathrm{Cl}(0,1-20,7) \mathrm{p}=0,6$ \\
Intraoperative Los (\%) & $24(12,9)$ & $7(13,7)$ & $0,995 \% \mathrm{Cl}(0,3-2,3) \mathrm{p}=0,8$ \\
\hline
\end{tabular}

centres [25-32]. Moreover, we were not able to compare our group with those underwent TT with ipsilateral or bilateral central neck dissection because our study concerned patients with follicular proliferation/indeterminate cytology excluding those who underwent lymphadenectomies and thyroidectomies for benign diseases [33]. According ATA guidelines we performed therapeutic central-compartment (level VI) neck dissection for patients with clinically involved central nodes and prophylactic central-compartment neck dissection in patients with thyroid carcinoma with clinically uninvolved central neck lymph nodes (cN0) who have advanced primary tumors (T3 or T4) or clinically involved lateral neck nodes [9]. The low rate of hypoparathyroidism in the CT group could be due to functional recovery of the parathyroid glands after the injury caused at the first operation. Indeed, several studies have shown that devascularized glands require approximately 4 weeks to return to full function [34]. Furthermore, because dissecting the scar tissue at the excised lobe site is not necessary, there is an absence of scar tissue in the remnant lobe region; therefore, the complication rate is low in CT thyroidectomies after hemithyroidectomies. Because use of a harmonic scalpel and nerve monitoring may give a slight advantage in overall outcomes [35-37], we use these devices for all patients. In a recent metaanalysis that compared neuromonitoring with recurrent laryngeal nerve visualization, no differences were identified in the transient or permanent RLN palsy rates [38]. However, data from the literature show that nerve monitoring during completion thyroidectomy may decrease the RLN palsy risk [39]. Our study is the first in the literature to compare the rate of complications in patients undergoing total thyroidectomy and completion thyroidectomy for indeterminate cytology/follicular proliferation of nodules. The retrospective nature of the study and the presence of a non-homogeneous group of patients represent the main limitations.

\section{Conclusions}

Completion thyroidectomy following hemithyroidectomy can be performed with acceptable morbidity in patients with preoperative indeterminate cytology/follicular proliferation of thyroid nodules.

\begin{abstract}
Abbreviations
ATA: American Thyroid Association; CT: Completion Thyroidectomy; DTC: Differentiated Thyroid Cancer; EMG: Electromyography; IONM: Intraoperative neuro monitoring; LOS: Loss of Signal; RLN: Recurrent Laryngeal Nerve; TT: Total Thyroidectomy
\end{abstract}

\section{Acknowledgements \\ Not Applicable.}

\section{Authors' contributions}

All authors equally contributed to this work satisfying the following 4 criteria of the guidelines of the International Committee of Medical Journal Editors (ICMJE): GS1 \& GG contributed equally to this work: Substantial contributions to the conception and design of the work; acquisition, analysis, and interpretation of data for the work; Drafting the work and revising it critically for important intellectual content; Final approval of the version to be published; Agreement to be accountable for all aspects of the work in ensuring that questions related to the accuracy and integrity of any part of the work are appropriately investigated and resolved. NL \& MT contributed equally to this work: Substantial contributions to the conception and design of the work; Drafting the work and revising it critically for important intellectual content. NI, RS \& GS2 contributed equally to this work: Substantial contributions to the conception or design of the work; acquisition, analysis and interpretation of data for the work; Drafting the work and revising it critically for important intellectual content. All authors have read and approved the manuscript.

\section{Funding}

No funding was obtained for this study.

\section{Availability of data and materials}

The datasets used and/or analyzed during the current study available from the corresponding author on reasonable request. Data obtained for our study was publically availible under 'methods'.

\section{Ethics approval and consent to participate}

The study was approved by Ethics Commitee of "Magna Graecia" University. All procedures performed in studies involving human participants were in accordance with the ethical standards of the institutional and/or national research Commitee and with the 1964 Helsinki declaration and its later amendments or comparable ethical standards.

Written informed consent was obtained from all participants included in the study.

\section{Consent for publication}

Not Applicable.

\section{Competing interests}

The authors declare that they have no competing interest.

Received: 29 November 2018 Accepted: 2 July 2019

Published online: 10 July 2019

\section{References}

1. Davies L, Welch HG. Current thyroid cancer trends in the United States. JAMA Otolaryngol Head Neck Surg. 2014;140(4):317-22. 
2. Vaccarella S, Franceschi S, Bray F, Wild CP, Plummer M, Dal Maso M. Worldwide thyroid-Cancer epidemic? The increasing impact of Overdiagnosis. N Engl J Med. 2016;375(7):614-7.

3. Jung KW, Won YJ, Kong HJ, Oh CM, Cho H, Lee DH, et al. Cancer statistics in Korea. Incidence, mortality, survival, an.D prevalence in 2012. Cancer Res Treat. 2015:47(2):127-41.

4. Clark OH, Levin K, Zeng Q, Greenspan FS, Siperstein A. Thyroid cancer: the case for total thyroidectomy. Eur J Clin Oncol. 1988;24:305-13.

5. Mazzaferri EL. An overview of the management of papillary and follicular carcinoma. Thyroid. 1999;9:421-7.

6. Levin $\mathrm{KE}$, Clark AH, Duh Q-Y, Demeure M, Siperstein AE. Clark.Reoperative thyroid surgery. Surgery. 1992;111:604-9.

7. Hay ID, Grant CS, Bergstralh EJ, Thompson GB, Van Heerden JA, Goellner JR. Unilateral thyroid lobectomy: is it sufficient surgical treatment for patients with AMES low risk papillary thyroid carcinoma? Surgery. 1988;124:958-66.

8. Cady B, Rossi RL. An expanded view of risk group definition in differentiated thyroid carcinoma. Surgery. 1988;104:947-53.

9. American Thyroid Association (ATA) Guidelines Taskforce on Thyroid Nodules and Differentiated Thyroid Cancer, Cooper DS, Doherty GM, Haugen BR, Kloos RT, Lee SL, et al. Revised American Thyroid Association management guidelines for patients with thyroid nodules and differentiated thyroid cancer. Thyroid. 2009;19:1167-214.

10. Schlumberger MJ. Medical progress-papillary and follicular thyroid carcinoma. N Engl J Med. 1998;338:297-306.

11. Rosario PW, Fagundes TA, Borges MAR, Padrao EL, Rezende LL, Barroso AL, et al. Completion thyroidectomy in patients with thyroid carcinoma initially submitted to lobectomy. Clin Endocrinol. 2004;61:652-3.

12. Pisello F, Geraci G, Sciumè C, Li volsi F, Facella T, Modica G. Prevention of complications in thyroid surgery recurrent laryngeal nerve injury personal experience on 313 cases. Ann Ital Chir. 2005;76:23-8

13. Tezelman S, Borucu I, Senyurek Giles $Y$, Tunca F, Terzioglu T. The change in surgical practice from subtotal to near-total or total thyroidectomy in the treatment of patients with benign multinodular goiter. World J Surg. 2009; 33:400-5.

14. Randolph GW, Dralle H, Abdullah H, Barczynski M, Bellantone R, Brauckhoff, et al. Electrophysiologic recurrent laryngeal nerve monitoring during thyroid and parathyroid surgery: international standards guideline statement. Laryngoscope. 2009:121:1-16.

15. Kluijfhout WP, Pasternak JD, Lim J, Kwon JS, Vriens MR, Clark OH, et al. Frequency of high-risk characteristics requiring total thyroidectomy for 1-4 cm well-differentiated thyroid cancer. Thyroid. 2016;(6):820-4.

16. Alzahrani AS, Al Mandil M, Chaudhary MA, Ahmed M, Mohammed GE. Frequency and predictive factors of malignancy in residual thyroid tissue and cervical lymph nodes after partial thyroidectomy for differentiated thyroid cancer. Surgery. 2002;131:443-9.

17. Kim ES, Kim TY, Koh JM, Kim YI, Hong SJ, Kim WB, et al. Completion thyroidectomy in patients with thyroid cancer who initially underwent unilateral operation. Clin Endocrinol. 2004;61:145-8.

18. Ibrahim B, Forest VI, Hier M, Mlynarek AM, Caglar D, Payne RJ. Completion thyroidectomy: predicting bilateral disease. J Otolaryngol Head Neck Surg. 2015;44:23.

19. Esnaola NF, Cantor SB, Sherman SI, Lee JB, Evans DB. Optimal treatment strategy in patients with papillary thyroid cancer: a decision analysis. Surgery. 2001;130:921-30.

20. Lee HS, Roh JL, Gong G, Cho KJ, Choi SH, Nam SY, et al. Risk factors for rerecurrence after first reoperative surgery for locoregional recurrent/ persistent papillary thyroid carcinoma. World J Surg. 2015;39:1943-50.

21. Hay ID, Grant CS, Bergstralh EJ, Thompson GB, Van Heerden JA, Goellner JR. Unilateral total lobectomy: is it sufficient surgical treatment for patients with AMES low-risk papillary thyroid carcinoma. Surgery. 1998;124:958-66.

22. Bilimoria KY, Zanocco K, Sturgeon C. Impact of surgical treatment on outcomes for papillary thyroid cancer. Adv Surg. 2008:42:1-12.

23. Bal CS, Kumar A, Pant GS. Radioiodine lobar ablation as an alternative to completion thyroidectomy in patients with differentiated thyroid cancer Nucl Med Commun. 2003;24:203-8.

24. Li YJ, Wang YZ, Yi ZB, Zhou ZD. Comparison of completion thyroidectomy and primary Total surgery for differentiated thyroid Cancer: a meta-analysis. Oncol Res Treat. 2015;38:528-31.

25. Erdem E, MA Ge, Kuru B, Alagol H. Comparison of completion thyroidectomy and primary surgery for differentiated thyroid carcinoma. Eur J Surg Oncol. 2003;29:747-9.
26. Rafferty MA, Goldstein DP, Rotstein L, Asa SL, Panzarella T, Gullane P, et al. Completion thyroidectomy versus total thyroidectomy: is there a difference in complication rates? An analysis of 350 patients. J Am Coll Surg. 2007;205: 602-7.

27. Gulcelik MA, Kuru B, Dincer H, Camlibel M, Yuksel UM, Yenidogan, et al. Complications of completion versus total thyroidectomy. Asian Pac J Cancer Prev. 2012;13:5225-8.

28. Eroğlu A, Unal M, Kocaoğlu H. Total thyroidectomy for differentiated thyroid carcinoma: primary and secondary operations. Eur I Surg Oncol. 1998;24: 283-7.

29. Rosario PW, Pereira LF, Padr. OEL, Rezende LL, Barroso AL, Purisch. Comparison of completion thyroidectomy and primary surgery for thyroid carcinoma. ANZ J Surg. 2007;77:305.

30. Merchavy S, Marom T, Forest VI, Hier M, Mlynarek A, McHugh T, et al. Comparison of the incidence of postoperative hypocalcemia following total thyroidectomy vs completion thyroidectomy. Otolaryngol Head Neck Surg. 2015;152:53-6.

31. Mishra A, Mishra SK. Total thyroidectomy for differentiated thyroid cancer: primary compared with completion thyroidectomy. Eur I Surg. 2002;168: 283-7.

32. Conzo G, Polistena A, Calò PG, Bononi P, Gambardella C, Mauriello C, et al. Efficacy of combined treatment of anaplastic thyroid carcinoma: results of a multinstitutional retrospective analysis. Int I Surg. 2014;12(Suppl 1):S178-82.

33. Calò PG, Conzo G, Raffaelli M, Medas F, Gambardella C, De Crea C, et al. Total thyroidectomy alone versus ipsilateral versus bilateral prophylactic central neck dissection in clinically node-negative differentiated thyroid cancer. A retrospective multicentre study. Eur I Surg Oncol. 2017;43(1):12632.

34. El-Sharaky MI, Kahalil MR, Sharaky O. Assessment of parathyroid autotransplantation for preservation of parathyroid function after total thyroidectomy. Head Neck. 2003;25:799-807.

35. Foreman E, Aspinall S, Bliss RD, Lennard TW. The use of the harmonic scalpel in thyroidectomy: 'beyond the learning curve'. Ann R Coll Surg Engl. 2009;91:214-6.

36. Thomusch O, Sekulla C, Walls G, Machens A, Dralle H. Intraoperative neuromonitoring of surgery for benign goitre. Am J Surg. 2002;183:673-8.

37. Tamura A, Tsutsui H, Yano Y, Ohara R, Hoshi M, Nagai T, et al. Thermal effects of the Thunderbeat ${ }^{\text {TM }}$ device on the recurrent laryngeal nerve during thyroid surgery. Surg Today. 2018:48:1076-80.

38. Pisanu A, Porceddu G, Podda M, Cois A, Uccheddu A. Systematic review with meta-analysis of studies comparing intraoperative neuromonitoring of recurrent laryngeal nerves versus visualization alone during thyroidectomy. Surg Res. 2014;188:152-61.

39. Barczynski M, Konturek A, Stopa M, Honowska A, Nowak W. Randomized controlled trial of visualization versus neuromonitoring of the external branch of the superior laryngeal nerve during thyroidectomy. World I Surg. 2012;36:1340-7.

\section{Publisher's Note}

Springer Nature remains neutral with regard to jurisdictional claims in published maps and institutional affiliations.

Ready to submit your research? Choose BMC and benefit from:

- fast, convenient online submission

- thorough peer review by experienced researchers in your field

- rapid publication on acceptance

- support for research data, including large and complex data types

- gold Open Access which fosters wider collaboration and increased citations

- maximum visibility for your research: over $100 \mathrm{M}$ website views per year

At BMC, research is always in progress.

Learn more biomedcentral.com/submissions 